\title{
Recycling of hard-core smokers with nicotine nasal spray
}

\author{
P. Tønnesen, K. Mikkelsen, J. Nørregaard, S. Jørgensen
}

\begin{abstract}
Recycling of hard-core smokers with nicotine nasal spray. P. Tonnesen, K. Mikkelsen, J. Nфrregaard, S. Jørgensen. CERS Journals Ltd 1996.

ABSTRACT: The primary aim of this smoking cessation study was to evaluate the effect of long-term treatment with nicotine nasal spray in a group of hard-core smokers. A further aim was to compare the effect of ad libitum with fixed dosage of nasal nicotine spray.

Eighty nine smokers, failures from two earlier studies with nicotine patches, were enrolled in an open smoking cessation study with nicotine nasal sprays, to be used ad libitum $(n=45)$ or on a fixed schedule of $1 \mathrm{mg} \cdot \mathrm{h}^{-1}$ during the day $(\mathrm{n}=$ 44).

Carbon monoxide-verified continuous abstinence from smoking beyond Week 2, was $39 \%$ at 3 weeks, $12 \%$ at 3 months, $10 \%$ at 6 months and $6 \%$ after $1 \mathrm{yr}$, with no significant difference in success rate between ad libitum and fixed dosing. Mean daily nicotine dose was 15-16 mg during the first 3 months (range 2-65 mg). Tolerance to local irritating side-effects of nicotine developed during the first weeks of use.

Although short-term outcome was promising, the long-term success rate in this group of hard-core smokers was low. Other recycling set-ups are warranted, which might include more aggressive nicotine dosing.

Eur Respir J., 1996, 9, 1619-1623.
\end{abstract}

Dept of Pulmonary Diseases, Bispebjerg Hospital and Gentofte Hospital, Copenhagen, Denmark.

Correspondence: P. Tønnesen

Rudolph Berghs Gade 20

2100 Copenhagen $\varnothing$

Denmark

Keywords: Nasal spray

nicotine

side effects

smoking cessation

Received: September 41995

Accepted after revision March 251996
To attain an acceptable long-term success rate in smoking cessation, some basic principles have to be followed. The most important is that from the target quit day the smokers have to quit cigarettes completely; even a single cigarette on a few occasions ("slips") will probably lead to relapse.

The role of nicotine replacement with nicotine chewing gum and transdermal patches in smoking cessation has been established through several placebo-controlled clinical trials $[1,2]$, and a doubling of the success rate can be expected $[3,4]$. The dose and the duration of nicotine replacement therapy has not been fully evaluated, though a duration of 6-12 weeks is recommended in most studies, and dose-response effects have been found for nicotine gum and patch [3]. The easiest nicotine product to use is the patch; when applied to the skin it releases about 1 $\mathrm{mg}$ of nicotine per hour, i.e. a fixed dosing system. Nicotine nasal spray (NNS), inhaler and gum have to be used ad libitum or prescribed to be taken every hour or so, with the possibility of self-regulating the dose when needed.

Trials comparing the four different nicotine formulations have not been performed. In a meta-analysis, comprising 17,703 subjects and 42 gum studies, nine patch studies, one NNS and one inhaler study, the odds rates of nicotine therapy compared with controls were 1.61 for gum, 2.07 for patch, 2.92 for NNS and 3.05 for inhaler [5]. The possible role of nasal aerosols in smoking cessation have been sparsely examined [6-9]. The NNS is the nicotine delivery system most closely like smoking cigarettes, due to the fast nicotine absorption from the nasal mucosa.
In two well-designed, controlled trials of NNS, comprising 227 and 248 smokers, the 1 year outcomes were 26 and $27 \%$ in the active group compared with 10 and $15 \%$ in the placebo groups $[10,11]$. In one study, a nicotine substitution of $40 \%$ of the smoking level was attained after 1 month of NNS use and 79\% after 1 year [10]. However, the nicotine level was measured 5 min after a $1 \mathrm{mg}$ dose of NNS as peak concentrations, and thus might have substantially overestimated the degree of nicotine substitution. For the recalcitrant smoker in the present study, the advantages of the NNS might be induction of fast and high peak nicotine concentrations, and the possibility of using the NNS whenever needed as a rescue to suppress craving in high risk situations and, thus, prevent relapse to cigarettes.

As smoking cessation may be regarded as a cyclical process, recycling of failures from smoking cessation trials seems obvious in order to improve long-term outcome. In a previous recycling study, we treated 126 failures from an earlier placebo-controlled nicotine patch study with active nicotine patches and individualized the dose according to the smoking cotinine levels [12]. Although the success rate in the recycling study was $50 \%$ after 3 weeks of treatment, all former nicotine-treated subjects had relapsed within 6 months.

The primary aim of this study was to evaluate the success rate with long-term treatment with NNS in this group of primary/secondary failures (i.e. hard-core smokers) in smoking cessation. A further aim was to compare ad libitum with fixed dosage of NNS. 


\section{Methods}

\section{Subjects}

All subjects were failures from two nicotine patch studies $[12,13]$. The "original" patch study comprised 289 smokers, 145 received active nicotine and 145 had placebo patches [13]. After 1 year, 126 failures participated in an open recycling study with nicotine patches [12]. After 2 yrs, 244 subjects were still smokers, and they received an invitation to participate in the present study [14] (fig. 1).

Approximately 100 subjects attended the clinic and the 89 interested subjects were enrolled, 45 subjects were allocated to ad libitum dosing and 44 subjects to fixed dosing. Of the 89 subjects enrolled: 31 subjects had received active patch twice with an interval of $1 \mathrm{yr}$, i.e. originally and after $1 \mathrm{yr}$ in the recycling study; 32 subjects had placebo patch followed by active patch; 14 subjects only had active patch once; and 12 subjects had received placebo patch once. Thus, $71 \%$ of the subjects had been recycled and relapsed twice, and $87 \%$ of the subjects had received active nicotine patch at least once.

Demographic data and smoking variables are presented in table 1. Most subjects were healthy (58\%), but 13 suffered from chronic obstructive pulmonary disease (COPD), one had angina pectoris, three diabetes mellitus, three arterial hypertension, six bronchial asthma, and 11 had other diseases. Twenty eight subjects were on daily medication (15 bronchodilators, 10 hormones, including contraceptives, and 19 other drugs).

\section{Study design}

This was an open randomized study with active NNS Inclusion criteria were: smokers willing to follow the protocol and motivated to quit smoking completely. Exclusion criteria were: pregnancy and breast-feeding, severe

$$
\begin{array}{lll}
\text { Year } & 2 \longrightarrow 3 \\
0 & 2 \longrightarrow \text { Recycling patch: } & \text { Recycling NNS: } \\
\text { Patch study: } & 89 \text { subjects } \\
145 \text { active patch } 126 \text { active patch } & 45 \text { ad libitum } \\
144 \text { placebo patch } & 44 \text { fixed dose }
\end{array}
$$

Fig. 1. - Study design. NNS: nicotine nasal spray.

Table 1. - Demographic data and smoking variables for the 89 subjects

\begin{tabular}{lclcl}
\hline Variable & \multicolumn{2}{c}{$\begin{array}{c}\text { Fixed dose } \\
\mathrm{n}=44\end{array}$} & \multicolumn{2}{c}{ Ad libitum } \\
$\mathrm{n}=45$
\end{tabular}

Results are mean \pm SD. *: machine smoked nicotine delivery. M: male; F: female; FTND: Fagerström Tolerance Nicotine Dependence score. or symptomatic cardiovascular disease, severe or unstable asthma and COPD, chronic nasal disease, abuse of alcohol and drugs, regular use of psychotropic medication, and use of smokeless tobacco. Eight (or nine) visits during 1 year were planned (Week 0, 1, 2, 3 and 6, and months $3,6,(9)$ and 12). The first visit to the clinic was the target quit day, when all subjects were told to stop smoking abruptly and to start using the NNS. At the first visit, a medical history was obtained and supportive written material delivered. At each session, the assessments were followed by group meetings with 10-12 participants lasting 20-40 min, chaired by one physician. Most time was devoted to round-table discussion, when the participants talked about their experience of quitting smoking and use of the NNS.

\section{Assessments}

At each visit, smoking status was asked for, body weight was measured, and carbon monoxide was measured using a CO-analyser (Bedfont EC 50 CO Monitor, UK) in endexpiratory air after a $15 \mathrm{~s}$ breathhold [15]. An unstimulated salivary sample of at least $3 \mathrm{~mL}$ was collected in a plastic cup, stored at $-20^{\circ} \mathrm{C}$ within $2 \mathrm{~h}$, and later analysed for cotinine level by a fluorescence polarization immunoassay method [16].

At all visits, subjects were questioned as follows: 1) 14 withdrawal-related symptoms [17] for the last $24 \mathrm{~h}$ were scored on a five point scale: not at all $=0$, somewhat $=$ 1 , moderately so $=2$, very much so $=3$, markedly so $=4 ; 2$ ) possible adverse events from the NNS scored as none, mild, moderate or severe, as judged by the patient.

The following scales were completed: 1) the Fagerström Tolerance Nicotine Dependence (FTND) Questionnaire [18]; 2) stress intensity (0-3) and frequency (0-3); 3 ) satisfaction with life during the preceding year $(0-2)$; 4) motivation to quit $(0-4) ; 5)$ fear of weight gain $(0-4)$; 6) urge to smoke $(0-4)$.

\section{Nicotine therapy}

The NNS (Pharmacia AB, Helsingborg, Sweden) consists of a hand-driven nasal pump spray. The bottle contains $10 \mathrm{~mL}$ of nicotine solution $\left(10 \mathrm{mg} \cdot \mathrm{mL}^{-1}\right)$ with a preservative. Each puff delivers $50 \mu \mathrm{L}$, equal to $0.5 \mathrm{mg}$ of nicotine. Subjects were instructed to spray one puff into each nostril at each administration, i.e. a dose of 1 $\mathrm{mg}$ of nicotine.

Subjects were allocated to fixed dosing, i.e. $1 \mathrm{mg} \cdot \mathrm{h}^{-1}$ when awake, or ad libitum dosing, i.e. up to $5 \mathrm{mg} \cdot \mathrm{h}^{-1}$

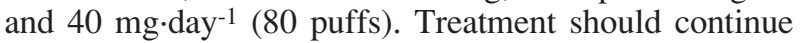
for 6 months, but tapering could be initiated after 3 months depending on the severity of withdrawal symptoms. Treatment could be continued for up to 12 months. The subjects registered the number of puffs used daily in a patient diary.

\section{Measure of outcome}

"Continuous abstainers" were defined as subjects completely abstinent from Week 2 until end-point and with a CO-level below 10 parts per million (ppm). 
"Abstainers with slips" were defined as occasionally smoking between two visits, i.e. unlimited smoking for $24 \mathrm{~h}$ followed by up to 5 days of smoking less than $15 \%$ of the number of cigarettes smoked at entry, however, the CO-level should be below $10 \mathrm{ppm}$ as above.

A subject not attending a visit was contacted by phone and eventually letter. Subjects lost to follow-up were assumed to be smokers. All randomized subjects were included in the outcome calculations.

\section{Ethics}

The study was approved by the local Ethics Committee and informed consent was obtained from all subjects.

\section{Statistics}

Demographic variables were described as mean and SD. Standard statistical tests were used, with a significance level of 0.05. Pearson Chi-squared test was used for categorical variables.

\section{Results}

The CO-verified sustained success rate plus/minus slips is shown in table 2 . The 3 weeks success rate without slips was $39 \%$ declining to $6 \%$ at the 12 months followup, and $9 \%$ with slips allowed. There was no statistical difference in outcome at any time between the ad libitum and fixed dosing groups.

Table 2. - Success rates for the 89 subjects as sustained abstinence without and with slips (percent)

\begin{tabular}{lcccccc}
\hline Time period & \multicolumn{6}{c}{ Sustained abstinence rate \% } \\
& $\begin{array}{c}\text { Without slips } \\
\text { (45) }\end{array}$ & $\begin{array}{c}\text { Fixed } \\
(44)\end{array}$ & $\begin{array}{c}\text { All } \\
(89)\end{array}$ & $\begin{array}{c}\text { Ad lib } \\
\text { (45) }\end{array}$ & $\begin{array}{c}\text { Fixed } \\
(44)\end{array}$ & $\begin{array}{c}\text { All } \\
(89)\end{array}$ \\
\hline 3 weeks & 40 & 39 & 39 & 56 & 57 & 56 \\
6 weeks & 27 & 20 & 24 & 44 & 41 & 43 \\
3 months & 16 & 912 & 27 & 18 & 23 & \\
6 months & 13 & 710 & 16 & 11 & 14 & \\
12 months & 7 & 56 & 9 & 7 & 9 & \\
\hline
\end{tabular}

Numbers in brackets represent number of subjects.
Nicotine substitution, as measured by plasma cotinine, was 26-38\% smoking levels (table 3 ) during the first 3 months. The participants used 15-16 doses daily during the first 3 months (range of 2-65). There was no difference between the two dosing regimens except for a tendency to a wider range of doses during the first 3 weeks in the ad libitum group.

Side-effects for the last $24 \mathrm{~h}$ at each visit appeared mainly as local irritating effects from nicotine in the nose, eyes and throat, decreasing during the first weeks (table 4). Moderate and severe side-effects are shown in table 4 ; however, $80 \%$ reported nasal irritation after 1 week of NNS use, declining to $61 \%$ after 2 weeks. On openended questions, nine subjects $(10 \%)$ reported blood in nasal discharge and nose bleeding.

Systemic side-effects were few and nobody had to stop treatment with the NNS due to side-effects. However, two subjects disliked the NNS and only used it for 1-2 days. The increase in body weight in abstainers was 1.0 (SD 2.0) kg after 3 months, 3.0 (SD 3.8) $\mathrm{kg}(\mathrm{p}<0.05)$ after 6 months, and 4.4 (sD 2.3) kg ( $<<0.05)$ after 12 months. No tendency to a lesser weight gain was found in daily users of the NNS.

As all subjects received active NNS, the influence on withdrawal symptoms cannot be properly evaluated. However, changes in score from smoking baseline compared with abstinence after 1 week showed increase

Table 4. - Moderate and severe side-effects from NNS use up to 6 weeks in percentage at each visit for the last $24 \mathrm{~h}$

\begin{tabular}{lccrr}
\hline Symptom & $\begin{array}{c}\text { Week 1 } \\
(\mathrm{n}=74)\end{array}$ & $\begin{array}{c}\text { Week 2 } \\
(\mathrm{n}=56)\end{array}$ & $\begin{array}{c}\text { Week 3 } \\
(\mathrm{n}=50)\end{array}$ & $\begin{array}{r}\text { Week 6 } \\
(\mathrm{n}=43)\end{array}$ \\
\hline Nasal irritation & $23 / 22^{*}$ & $17 / 7$ & $14 / 4$ & $17 / 5$ \\
Pain in nose & $20 / 22$ & $17 / 9$ & $10 / 2$ & $9 / 5$ \\
Nasal blockage & $7 / 4$ & $2 / 2$ & $4 / 4$ & $7 / 2$ \\
Nasal discharge & $16 / 19$ & $18 / 9$ & $12 / 2$ & $14 / 0$ \\
Sneezing & $16 / 6$ & $9 / 4$ & $6 / 2$ & $7 / 0$ \\
Irritation in throat & $8 / 10$ & $4 / 2$ & $6 / 2$ & $5 / 0$ \\
Coughing & $5 / 5$ & $2 / 2$ & $0 / 0$ & $5 / 0$ \\
Watering eyes & $8 / 7$ & $2 / 2$ & $0 / 2$ & $0 / 0$ \\
Irritation in eyes & $4 / 5$ & $0 / 0$ & $0 / 0$ & $5 / 0$ \\
Palpitations & $1 / 1$ & $2 / 0$ & $0 / 0$ & $0 / 0$ \\
Cold sweat & $0 / 0$ & $0 / 2$ & $0 / 0$ & $0 / 0$ \\
Headache & $1 / 4$ & $2 / 2$ & $0 / 0$ & $10 / 0$ \\
Dizziness & $3 / 0$ & $0 / 0$ & $0 / 0$ & $0 / 0$ \\
\hline
\end{tabular}

*: $23 / 22=$ moderate in $23 \%$ and severe in $22 \%$

Table 3. - Saliva cotinine concentrations and number of NNS doses daily up to 6 months in subjects with slips and in abstainers reporting daily use of NNS

\begin{tabular}{|c|c|c|c|c|c|c|c|c|c|c|}
\hline \multirow[b]{3}{*}{ Time } & \multicolumn{4}{|c|}{ Subjects with slips } & \multicolumn{4}{|c|}{ Abstinent subjects } & \multirow{2}{*}{\multicolumn{2}{|c|}{$\begin{array}{c}\text { All subjects } \\
\text { NNS }\end{array}$}} \\
\hline & \multirow[b]{2}{*}{$\mathrm{n}$} & \multicolumn{3}{|c|}{ Cotinine conc. $\mathrm{ng} \cdot \mathrm{mL}^{-1}$} & \multirow[b]{2}{*}{$\mathrm{n}$} & \multicolumn{3}{|c|}{ Cotinine conc. $\mathrm{ng} \cdot \mathrm{mL}^{-1}$} & & \\
\hline & & $\% *$ & mean & SD & & $\% *$ & mean & SD & doses $\cdot$ day $^{-1}$ & range \\
\hline Entry & 29 & 100 & 433 & 141 & 26 & 100 & 443 & 110 & \multicolumn{2}{|c|}{ smoking } \\
\hline 1 week & 29 & 52 & 230 & 90 & 26 & 26 & 116 & 76 & 16 & $2-65$ \\
\hline 2 weeks & 12 & 30 & 140 & 88 & 38 & 28 & 125 & 95 & 16 & $2-50$ \\
\hline 3 weeks & 15 & 35 & 174 & 102 & 31 & 31 & 136 & 103 & 16 & $3-40$ \\
\hline 6 weeks & 11 & 31 & 134 & 67 & 24 & 29 & 138 & 66 & 16 & $7-52$ \\
\hline 3 months & 5 & 58 & 327 & 222 & 14 & 38 & 160 & 117 & 15 & $3-30$ \\
\hline 6 months & 1 & 119 & 437 & & 4 & 14 & 58 & 73 & 6 & $3-15$ \\
\hline
\end{tabular}

One NNS dose $=1$ puff in each nostril, i.e. $1 \mathrm{mg}$ nicotine. NNS: nicotine nasal spray. ${ }^{*}$ : expressed as a percentage of the smoking value. 
(approximately doubling) in the following symptoms: urge to smoke, irritability, impatience, restlessness, concentration difficulties, anger, depression, excessive hunger, and food intake above normal. The following symptoms were unchanged: headache, drowsiness, sleep disturbance, and anxiety. There was a decrease in insomnia. Scores were generally low, i.e. "urge to smoke": 0.60 increasing to 1.63 (scale 0-4); and "food intake above normal": 0.11 increasing to 0.90 as the extremes.

Stress was scored low ("How much stress": $23 \%$ not at all, $37 \%$ slightly, $23 \%$ some, $10 \%$ very much) ("How often": $35 \%$ almost never, $25 \%$ sometimes monthly, $22 \%$ sometimes weekly, $18 \%$ every day). Motivation to quit high was scored high (42\% very much, $50 \%$ much, $8 \%$ moderate and slight). The concern about gain in body weight was relatively pronounced $(36 \%$ very much concerned, $8 \%$ much, $15 \%$ moderate, $17 \%$ slight, $23 \%$ not at all). The answers on "satisfaction with life last year" were $39 \%$ very satisfied, $48 \%$ satisfied, and $13 \%$ not satisfied.

On the question "Will you succeed in quitting smoking?", $60 \%$ answered yes, $17 \%$ maybe, and $24 \%$ do not know.

\section{Discussion}

Recycling with NNS combined with psychological support showed a relatively low success rate, comparable with the success rate in our first recycling study with nicotine patches [12]. Excluding the 12 subjects who had only received placebo patch before - thus, only focusing on recycling of smokers who had received nicotine therapy before - reduces the 1 year success rate from 5.6 to $3.9 \%$. The 3 month success rate in the present study (23\%) was lower than original nicotine patch study (41\%) $(\mathrm{p}<0.01)$, from which the present failures were recruited.

The 1 year result is also low compared with the 26 , 27 and $27 \%$ in the three published studies with nicotine nasal spray $[10,11,19]$; however, it has to be remembered that our sample of smokers are failures from 1-2 earlier studies and, thus, should be regarded as "hardcore" smokers.

Undersubstitution with nicotine may have played a major role in the low success rate of the present study. The nicotine substitution attained was from $25-33 \%$ of the smoking levels, comparable with the substitution achieved using a low-dose nicotine patch [3, 13]. Two dosage regimens were used, however, no difference was observed between the fixed and ad libitum dosing group. With a mean daily dose of $16 \mathrm{mg}$ nicotine, most subjects have in fact used the NNS once every hour as prescribed. In further studies, at least a doubling of dose should be tried as dose-response effects have been found for nicotine patches [20]. The cotinine levels attained with the NNS probably overestimate the "pharmacologically" active nicotine, as a variable amount of each puff in the nostrils is swallowed. On the other hand, plasma cotinine only reflects the cumulative dose of nicotine, but with the NNS the user attains fast and relatively high peak plasma nicotine levels 5-10 min after each dose, as reported by SuTHERLAND et al. [10]. Tolerance to the local side-effects of nicotine developed fast and most subjects could tolerate the NNS. However, it is important to give instruction and to let the subject try the first doses in the clinic under supervision, as the reaction to the first doses is usually severe, i.e. subjects often develop sudden sneezing, watery nasal discharge, strong burning sensation in the nose and coughing.

NNS should be tried in combination with nicotine patches, to ensure a basal substitution and still have the opportunity to use the "fast" nicotine dispenser, i.e. NNS. However, preliminary results from combined treatment with nicotine gum and patch have shown disappointing long-term results [21, 22]. Subjects were allowed to use the NNS up to one year in the above studies, thus longer treatment duration seems not to be the solution to improved outcome.

Besides the effect of the NNS, i.e. the pharmacological aspects of smoking dependence, the psychological factors might play an important role in the adherence to smoking in the present group of smokers. Regarding stress, withdrawal symptoms and motivation to quit, this group does not appear to be especially "difficult". The subjects own scoring of motivation was in fact high, and on the question "Do you believe you will quit smoking this time" $60 \%$ answered yes and $17 \%$ maybe, which could reflect a high degree of self-confidence. Also, in our clinical set-up, we incorporated much more behavioural and psychological group support compared with our previous studies.

As the smoking prevalence is decreasing in most European countries, the smoking population will contain an increasing proportion of hard-core smokers. Thus, it is relevant to conduct a larger randomized study with recycling of failures, focusing more specifically on psychological factors.

We have examined predictors of and reasons for relapse in the original patch study comprising 289 smokers, and found that previous attempts to quit smoking and low smoking saliva cotinine levels were associated with 6 weeks abstinence [23]. Also, "slips" was a significant predictor of relapse, and we focused on how to prevent slips in our group sessions.

Although a $6 \% 1$ year sustained abstinence rate seems disappointingly low, it has to be remembered that the "spontaneous" quit rate in the general population is approximately $1 \%$ yearly. Our model of recycling should be tested by others before the recycling concept is dropped. More intensive adjunctive behavioural therapy might be valuable in subjects primarily treated with nicotine. Also, individualization of nicotine replacement therapy might improve outcome. There is a lack of studies comparing the results of different nicotine formulations (i.e. patch, gum, nicotine nasal spray, inhaler) and also of studies combining the different nicotine formulations [24].

Acknowledgements: Pharmacia AB Consumer Pharma, Helsingborg, Sweden, is thanked for sponsoring the study and analysis of saliva for cotinine levels.

\section{References}

1. Surgeon General. The health consequences of smoking: nicotine addiction. US Department of Health and Human Services, USA, 1988. 
2. Smoking Cessation in 1994. Russel MAH, Fagerström KO, Benowitz N, Caldwell DS, eds. J Smoking Related Dis 1994; 5 (Suppl. 1); 3-328.

3. Tønnesen P, Fagerstrøm KO. Nicotine replacement. In: Richmond R, eds. Interventions for Smokers. USA, Williams \& Wikins, 1994; pp. 3-28.

4. Tønnesen P. Smoking cessation programs. In: Hansen $\mathrm{HH}$, ed. Lung Cancer. Boston, Kluwer Academic Publishers, 1994; pp. 75-89.

5. Silagy C, Mant D, Fowler G, Lodge M. Meta-analysis on efficacy of nicotine replacement therapies in smoking cessation. Lancet 1994; 343: 139-142.

6. Russell MAH, Jarvis MJ, Feyerabend C, Fernö O. Nasal nicotine solution: a potential aid to giving up smoking? BMJ 1983; 286: 683-684.

7. West RJ, Jarvis MJ, Russell MAH, Feyerabend C. Plasma nicotine concentrations from repeated doses of nasal nicotine solution. $\mathrm{Br} J$ Addict 1984; 79: 443-445.

8. Jarvis MJ, Hajek P, Russell MAH, West RJ, Feyerabend C. Nasal nicotine solution as an aid to cigarette withdrawal: a pilot clinical trial. Br J Addict 1987; 82: 983-988.

9. Perkins KA, Epstein LH, Stiller R, Jennings JR, Christiansen C, McCarthy T. An aerosol spray alternative to cigarette smoking in the study of the behavioral and physiological effects of nicotine. Behav Res Meth Inst Comp 1986; 18: 420-426.

10. Sutherland G, Stapleton JA, Russell MAH, et al. Randomised controlled trial of nasal nicotine spray in smoking cessation. Lancet 1992; 340: 324-329.

11. Hjalmarson A, Franzon M, Westin A, Wiklund O. Effect of nicotine nasal spray on smoking cessation. Arch Intern Med 1994; 154: 2567-2672.

12. Tønnesen P, Nørregaard J, Säwe U, Simonsen K. Recycling with nicotine patches in smoking cessation. Addiction 1993; 88: 533-539.

13. Tønnesen P, Nørregaard J, Simonsen K, Sawe U. A double-blind trial of 16 hour transdermal nicotine patch in smoking cessation. N Engl J Med 1991; 325: 311-315.

14. Mikkelsen KL, Tønnesen P, Nørregaard J. Three year outcome of two and three year sustained abstainers from a smoking cessation study with nicotine patches. J Smoking Related Dis 1994; 5(2): 95-100.

15. Jarvis MJ, Russell MA, Saloojee Y. Expired air carbon monoxide: a simple breath test of tobacco smoke intake. BMJ 1980; 281: 484-485.

16. Falkmann SE, Burrows IE, Lundgren RA, Page BFJ. A modified procedure for determination of nicotine in blood. Analyst 1975; 100: 99-104.

17. American Psychiatric Association. Diagnostic and Statistical Manual of Mental Disorders. 3rd edn. American Psychiatric Association, 1987.

18. Fagerström KO, Heatherton TF, Kozlowski LT. Nicotine addiction and its assessment. Ear Nose Throat J 1991; 69: 763-768.

19. Blöndal T, Franzon M, Westin A, Olafsdottir I, Gudmundsdottir S, Gunnarsdottir R. Controlled trial of nicotine nasal spray with long term follow-up. (Abstract). Am Rev Respir Dis 1993; 147: A806.

20. Transdermal Nicotine Study Group. Transdermal nicotine for smoking cessation: six month results from two multicenter controlled clinical trials. JAMA 1991; 266: 3133 3138.

21. Puska P, Vartiainen E, Korhonen H, Urjanheimo EL, Gustavsson G. Combining patch and gum in nicotine replacement therapy: results of a double-blind study in North Karelia (Abstract). J Smoking Related Dis 1994; 5 (Suppl. 1): 313.

22. Kornitzer M, Boutsen M, Dramaix M, Thijs J, Gustavsson G. Efficacy and safety of combining use of nicotine patch and nicotine gum in smoking cessation: a placebo-controlled, double-blind trial. Proceedings: Future Directions in Nicotine Replacement Therapy. Conference, Grand Hotel, Paris, October 1993, Adis, Chester 1994; pp. 83 84.

23. Nørregaard J, Tønnesen P, Petersen L. Predictors and reasons for relapse in smoking cessation with nicotine and placebo patches. Prev Med 1993; 22: 261-271.

24. Benowitz N. Nicotine replacement therapy. What has been accomplished - can we do better? Drugs 1993; 45: 157-170. 